\title{
GASES IN METALS: III. THE DETERMINATION OF NITROGEN IN METALS BY FUSION IN VACUUM
}

\author{
By Louis Jordan and James R. Eckman
}

\section{ABSTRACT}

A method has been developed for the determination of nitrogen in the gases evolved from metals fused in vacuum. As in a previously described method for the determination of oxygen and hydrogen by vacuum fusion, the metal sample is melted in a graphite crucible in a high-frequency vacuum furnace. The nitrogen, together with the other gases evolved except the noble gases, is absorbed in calcium vapor. The calcium nitride thus formed is dissolved in dilute hydrochloric acid with the formation of an ammonium salt, and the resulting ammonia is determined by distillation into a standard acid. The efficiency of the determination of nitrogen by absorption in calcium vapor was determined by tests with known gas mixtures. The complete vacuum-fusion procedure was applied to the analysis of several synthetic nitrides (silicon, aluminum; titanium, zirconium, chromium, vanadium) and a few irons and steels. The results obtained were compared with the nitrogen values given by the usual acid-solution method for nitrogen in metals. The fusion method has a precision equal to that of the solution method and gives higher values for nitrogen than the solution method in the analysis of nitrides of silicon, titanium, and vanadium and in certain iron and steel samples. The fusion method should determine also any "uncombined" nitrogen present in a metal.

\section{CONTENTS}

I. Introduction

II. Review of methods for determining nitrogen in gas mixtures_._._. $\quad 470$

III. Calcium as an absorbent for nitrogen ........ 471

IV. Method based on absorption of nitrogen in calcium vapor....... 472

1. Apparatus_._.

2. Reagents

3. Detailed procedure

V. Tests of method... 477

1. Blanks...

2. Analyses of known gas mixtures. 479

3. Analyses of nitrides

4. Analyses of irons and steels

VI. Summary and conclusions....... 484 


\section{INTRODUCTION}

The method usually employed for the determination of nitrogen in ferrous alloys has been some modification of the acid solution and distillation procedure. Wüst and Duhr ${ }^{1}$ have given a review of the development of this method and of the modifications introduced by various investigators up to the work of Tschischewski ${ }^{2}$ in 1915. Further work on the method has been reported by Wüst and Duhr, by Hurum and Fay, ${ }^{3}$ and by Jordan and Swindells. ${ }^{4}$

The various modifications of the method vary but little. All are based on the solution of the metal sample in an acid, usually hydrochloric, whereby the nitrogen present in the sample as nitrides is converted to the ammonium salt of the solvent acid. This acid solution is added to an excess of nitrogen-free caustic alkali, and the liberated ammonia is distilled off. The chief differences in the several modifications of the method lie in the manner of determining the ammonia in this distillate. This determination has been made either colorimetrically, by means of Nessler's reagent, or by iodometric or alkalimetric titration of the excess of a standard acid in which the distillate has been collected. The alkalimetric titration has been shown to be preferable to the Nessler method (Tschischewski, and Jordan and Swindells) and to the iodometric titration (Wüst and Duhr) when dealing with ferrous materials high in carbon. The results by all three methods differ but little as applied to the analysis of low-carbon ferrous alloys.

The solution method in its most satisfactory modification can be expected to determine only that nitrogen present in the metal samples in the form of nitrides which are soluble in the acid or acid mixture used for the solution of the sample. Iron nitride is readily soluble in acids, and the solution method should determine completely the nitride nitrogen in practically pure iron. Pig irons, cast irons, carbon steels, and alloy steels, however, may contain silicon, aluminum, chromium, vanadium, titanium, zirconium, and other elements which are known to form nitrides under some conditions, and certain of these nitrides are not readily soluble in acids. For example, Wüst and Duhr commented that in their analyses, by the solution method, of nitrogenized ferrochromium, ferroaluminum, and ferrovanadium the samples were only partially soluble. Tschischewski has also found that silicon and aluminum nitrides are not readily soluble in acids.

\footnotetext{
1 F. Wüst and J. Duhr, “Über eine Stickstoffbestimmungsmethode in Stahl und Roheisen usw." Mitt Kaiser-Wilhelm-Inst. Eisenforsch., 2, pp. 39-57; 1921.

${ }^{2}$ N. Tschischewski, "The occurrence and influence of nitrogen on iron and steel," J. Iron and Steel Inst., 92, II, pp. 47-90; 1915.

${ }^{3}$ F. Hurum and H. Fay, "The determination of nitrogen in steel," Chem. Met. Eng., 26, pp. 218-222; 1922.

- L. Jordan and F. E. Swindells, Gases in Metals: I. The Determination of Combined Nitrogen in Iron and Steel and the Change in Form of Nitrogen by Heat Treatment, B. S. Sci. Paper No. 457; 1922.
} 
There has also been a tendency, as remarked by Sawyer, ${ }^{5}$ to assume that nitrogen in some form other than "nitride nitrogen" may be present in ferrous alloys. Such nitrogen would presumably be present as a gas in pores of the metal, as "dissolved" nitrogen in the solid metal, or as adsorbed nitrogen on the crystal surfaces. The nitrogen present as a gas would be expected to escape determination by acid-solution methods. Whether or not nitrogen "dissolved" in the iron lattice is to be regarded as iron nitride and consequently determinable by an acid-solution method is not so evident.

Sawyer ${ }^{6}$ devised a combustion method for the determination of the total nitrogen in steels. The results obtained by this method were practically the same as the values given by the acid-solution method in the analysis of samples of highly nitrified iron and carbon steel; namely, ingot iron melted under nitrogen and cyanide-treated sheet iron. The method, however, was not developed to a point which gave results of sufficient precision to be serviceable in the analysis of materials containing nitrogen in amounts as low as those usually present in commercial ferrous alloys.

Vacuum-fusion methods for the extraction of gases from metals always show nitrogen in the collected gases. Tschischewski ${ }^{7}$ found that iron nitride melted and heated to $1,600^{\circ} \mathrm{C}$. retained no nitrogen. Andrew ${ }^{8}$ states that it was possible by heating at $1,000^{\circ} \mathrm{C}$. in a vacuum to extract almost entirely the nitrogen introduced into steel by melting under various pressures of nitrogen. Tschischewski also reports that manganese nitride begins to dissociate at about $1,000^{\circ} \mathrm{C}$., but indicates that silicon and aluminum nitrides are dissociated only at temperatures over $1,400^{\circ}$ and $1,750^{\circ} \mathrm{C}$., respectively. Tschischewski and Blinov ${ }^{9}$ found that vanadium nitride begins to dissociate above $1,300^{\circ} \mathrm{C}$. and titanium nitride above $1,500^{\circ} \mathrm{C}$.

The nitrogen liberated by the fusion of ferrous alloys in vacuum, therefore, may be due, in part, to the dissociation of some of those nitrides which are not readily soluble in the acid-solution method. Nitrogen gas in pores or blowholes and "dissolved" nitrogen-that is, uncombined nitrogen-should also be evolved by melting metals under very low pressures.

It therefore seemed desirable to adapt the vacuum-fusion procedure described by Jordan and Eckman ${ }^{10}$ to the determination of nitrogen in ferrous alloys, to apply the method to the recovery of nitrogen

SC. B. Sawyer, "The reactions and effects of nitrogen on steel-a supplementary review of literature," Trans. Am. Soc. Steel Treating, 8, pp. 291-308; 1925.

B C. B. Sawyer, "Nitrogen in steel," Trans. Am. Inst. Min. Met. Eng., 69, pp. 798-830; 1923.

7 See footnote 2, p. 468.

8 J. H. Andrew, "Iron and nitrogen," J. Iron Steel Inst. 86, II, pp. 210-240; 1912.

- N. Tschischewski and N. Blinov, "Titanium, vanadium, and nitrogen," Rev. soc. russe metall., I, p. 636; 1914; Chem. Abst., 10, p. 2685; 1916.

${ }_{10}$ L. Jordan and J. R. Eckman, Gases in Metals: II. The Determination of Oxygen and Hydrogen in Metals by Fusion in Vacuum, B. S. Sci. Paper No. 514; 1925. 
from synthetic nitrides, and to compare the results obtained from the analysis of some ferrous alloys by both the vacuum fusion and the acid-solution methods.

\section{REVIEW OF METHODS FOR DETERMINING NITROGEN IN GAS MIXTURES}

The metal samples were fused in vacuum for the extraction of nitrogen in the same manner as in the vacuum-fusion method for oxygen and hydrogen. The development of a suitable method for the determination of the nitrogen in the evolved gases was necessary.

The estimation of nitrogen as the residual gas after the volumetric determination of all other constituents is possibly the most familiar method. Nitrogen can also be determined by the thermal conductivity method ${ }^{11}$ or by means of the gas interferometer, ${ }^{12}$ but both of these methods require special and expensive apparatus and the use of a standard gas or mixture of gases. There remain several methods which involve the formation of some chemical compound of nitrogen. They may be grouped as "fixation" methods, since they involve reactions made familiar by reason of their use or suggested application to the fixation of atmospheric nitrogen.

The more important of these fixation methods are the formation of oxides of nitrogen, of ammonia from the direct union of nitrogen with hydrogen, of cyanides or cyanamide, and of metallic nitrides.

The formation of oxides of nitrogen has been applied to the quantitative analysis of nitrogen gas. The nitrogen is mixed with oxygen in a suitable gas pipette and electric sparks passed through the mixture. The oxides of nitrogen thus formed are then absorbed in a caustic alkali solution and the decrease in the total volume of the gas is measured. An improved apparatus for carrying out this determination has been described by Henrich and Eichhorn. ${ }^{13}$

The high temperatures and high pressures required for the direct synthesis of ammonia from nitrogen and hydrogen, as well as the comparatively low yield of ammonia, eliminate this reaction from consideration for use as an analytical method.

The reaction between calcium carbide and free nitrogen and the formation of ammonia from the resulting cyanide has been applied to the absorption of nitrogen by Fischer and Ringe ${ }^{14}$ and by Natus. ${ }^{15}$

11 E. R. Weaver, P. E. Palmer, H. W. Frantz, P. S. Ledig, and S. F. Pickering, "Automatic methods of gas analysis depending upon thermal conductivity," J. Ind. Eng. Chem. 12, pp. 359-366; 1920.

12 F. M. Seibert and W. C. Harpster, Use of the Interferometer in Gas Analysis, Bureau of Mines Tech. Paper No. 185; 1918. J. D. Edwards, Application of the Interferometer to Gas Analysis, B. S. Tech. Paper No. $131 ; 1919$.

13 F. Henrich and W. Eichhorn, "Über eine Apparatur durch die man Stickstoff aus Gasgemischen relativ rasch durch Funken quantitativ entfernen kann," Zeit. angew. Chem. 25, pp. 468-470; 1912.

14 F. Fischer and O. Ringe, "Die Darstellung von Argon aus Luft mit Calciumcarbid," Ber. deut. chem: Ges., 41, pp. 2017-2030; 1908.

${ }^{18}$ B. Natus, "Die direkte Bestimmung des elementaren Stickstoffs mit Hilfe von technischen Kalziumkarbid," Zeit. analyt. chem., 52, pp. 265-292; 1913. 
The method, as described by Natus, gives an average recovery of 99.25 per cent nitrogen as tested on the pure dry gas passed back and forth three times over the hot reaction mass of calcium carbide containing 10 per cent calcium chloride. When the reaction mass contained moisture, the recovery averaged only 96.4 per cent. The nitrogen in the reaction mass after absorption was determined by Wilfarth's modification of the Kjeldahl method.

A number of elements unite directly with free nitrogen to form nitrides. Rayleigh and Ramsay ${ }^{16}$ in describing methods for the removal of nitrogen from air, list the following elements as combining directly with nitrogen: Boron, silicon, titanium, strontium, barium, magnesium, aluminum, mercury, manganese, hydrogen, and oxygen. They used magnesium turnings at a bright red heat for the absorption of nitrogen after the removal of oxygen from the air. A review of metals and nonmetals available for the fixation of atmospheric nitrogen in the form of nitrides has been given by Norton. ${ }^{17} \mathrm{He}$ names lithium, calcium, and iron in addition to those listed above.

\section{CALCIUM AS AN ABSORBENT FOR NITROGEN}

The absorption of nitrogen by calcium and the resulting formation of calcium nitride has been studied by Maquenne, Moissan, Arndt, Soddy, and others.

Maquenne ${ }^{18}$ first attempted to prepare calcium nitride by distilling calcium amalgam in a current of nitrogen. The calcium nitride remained as a greenish-brown residue. In a later paper ${ }^{19}$ he described the rapid absorption of nitrogen by a mixture of magnesium and lime heated in a hard glass tube. He explained the absorption as being due to calcium formed by interaction of the lime and magnesium.

The use of mixtures of magnesium and lime with lithium or sodium as absorbents for nitrogen in gas analysis has been described by Dennis, ${ }^{20}$ and attention called to the present availability of metallic calcium and the possibility of its use directly in place of the mixtures which form calcium within the gas absorption apparatus.

Moissan ${ }^{21}$ found that pure calcium absorbed nitrogen at a dull red heat with the formation of calcium nitride. Arndt ${ }^{22}$ while

${ }^{16}$ Lord Rayleigh and William Ramsay, "Argon, a new constituent of the atmosphere," Phil. Trans. Roy. Soc., 186 (A), No. 1, pp. 187-251; 1895.

17 T.H. Norton, Utilization of Atmospheric Nitrogen, U. S. Bur. of Manufactures, Special Agents Series, No. 52, pp. 133-147; 1912.

${ }^{18}$ L. Maquenne, "Sur quelques propriétés des Metaux alcalino-terreux," Ann. Chem. Phys., 29 (6), pp. 215-227; 1893.

10 L. Maquenne, "Sur la fixation de l'azote par les metaux alcalino-terreux," Compt. Rend., 121, pp. 1147-1148; 1895.

20 L. M. Dennis, Gas Analysis, pp. 207-212; 1920.

${ }_{21}$ H. Moissan, "Préparation du calcium cristallisé," Compt. Rend., 126, pp. 1753-1758; "Préparation et propriétés de l'azoture de calcium," 12\%, pp. 497-501; 1898.

${ }^{22}$ K. Arndt, “Über das metallische Calcium," Ber. deut. chem. Ges., 37, p. 4733; 1904. 
heating calcium in a closed tube containing air at a pressure of about $15 \mathrm{~mm}$ noted that at $700^{\circ} \mathrm{C}$. there occurred an appreciable diminution of pressure, and at $730^{\circ} \mathrm{C}$. the pressure dropped in a few minutes to a value no longer readable, thus indicating complete absorption of the residual air. The absorption was accompanied by the volatilization of the calcium. At about $800^{\circ} \mathrm{C}$. the calcium insed. Soddy ${ }^{23}$ applied the absorptive power of calcium to the production of high vacua. He found that, in addition to oxygen and nitrogen, carbon monoxide, carbon dioxide, water vapor, acetylene, hydrogen, sulphur dioxide, ammonia, and oxides of nitrogen were readily and completely absorbed. He noted also the desirability of a high initial vacuum in order to vaporize the calcium properly.

\section{METHOD BASED ON ABSORPTION OF NITROGEN IN CALCIUM VAPOR}

The results of previous investigations have therefore shown calcium to be an efficient absorbent not only for nitrogen but also for a large number of other gases.

The attempt was made in the present investigation to determine nitrogen evolved from metals fused in vacuum by admitting the evolved gases to an evacuated tube containing vaporized calcium, absorbing all the gases except the noble gases in the calcium vapor, and finally determining the nitrogen in the resulting calcium nitride by dissolving the products of the absorption in hydrochloric acid and distilling ammonia from concentrated nitrogen-free sodium hydroxide into a standard sulphuric-acid solution. An evacuated absorption tube was used in order to accomplish absorption more rapidly by maintaining the vaporization of the calcium and in order to facilitate the flow of gases from the induction furnace into the absorption tube.

Such a procedure eliminates the necessity of using a gas-collecting vacuum pump and volumetric methods of analysis. It affords a means of absorbing the nitrogen rapidly and determining it easily and accurately without making measurements of the volume of the original or residual gas and without removing any other gases present with the nitrogen. The method may have application also in other types of gas analysis for the determination of nitrogen present in gas mixtures without the necessity of first removing other constituents.

\section{APPARATUS}

The apparatus used for the absorption of the nitrogen is shown in Figure 1. The furnace $A$ is an 8-inch nichrome-wound combustion furnace adjusted to give a temperature of $760^{\circ}$ to $780^{\circ} \mathrm{C}$., which is

${ }^{23}$ F. Soddy, "Calcium as an absorbent of gases for the production of high vacua, etc.," Proc. Roy. Soc., 78 (A), pp. 429-456; 1907. 
sufficient to vaporize the calcium. The heater and heat insulation of the furnace are incased in a sheet-iron jacket, split and hinged in a horizontal plane so that the hinged halves may be opened back from the combustion tube to permit rapid cooling.

The calcium is contained in an iron tube $B$, which is about 12 inches long and five-eighths inch in diameter and is placed within a silica combustion tube $C$. In the earlier part of this investigation an iron tube open at both ends was used. It was placed centrally in the furnace. In spite of the fact that both ends of the iron tube projected out of the furnace and attained a temperature which was still several hundred degrees below that at which the calcium vaporized, enough of the calcium vapor escaped from the iron tube to make the recovery of nitrogen low. This difficulty was overcome by using an iron tube closed at one end by forging. In this case the iron tube was placed in the combustion tube with its closed end within the

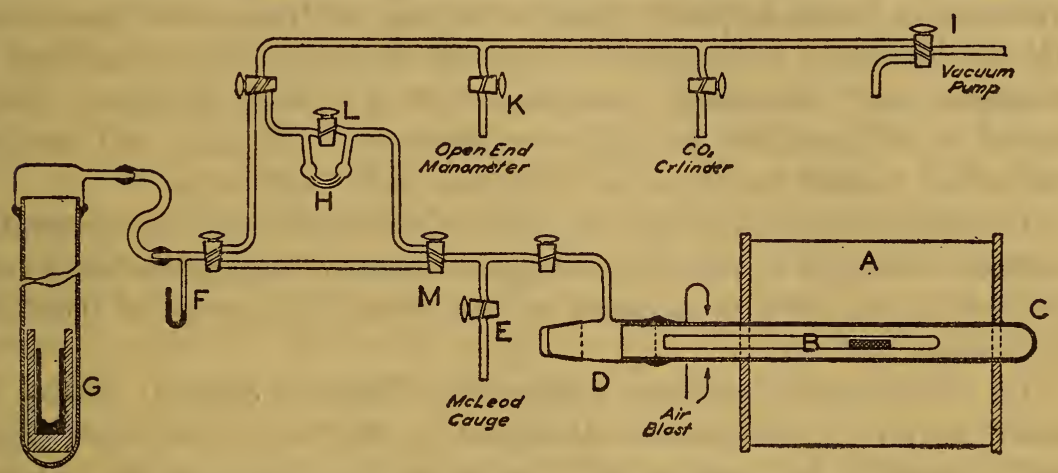

FIG. 1.-Apparatus for the absorption in calcium vapor of nitrogen evolved from metals fused in vacuum

heated zone of the furnace and its open end extending 7 or 8 inches beyond the end of the furnace toward the ground-glass closure. The combustion tube $C, 30$ inches long and 1 inch inside diameter, is closed at one end, and to the other and open end a glass tube $D$, fitted with a lubricated ground-glass cap, is sealed with hard de Khotinsky cement so as to permit the insertion or removal of the iron tube through the cap without disturbing the seal. The combustion tube is connected through the glass tube $D$ to a McLeod gauge at $E$, a manometer $F$, a vaporization indicator $H$, the induction furnace $G$, a vacuum pump at $I$, a carbon dioxide cylinder at $J$, and an open-end mercury manometer at $K$. A two-stage mercury vapor pump with a mechanical gear pump as a fore pump was used in the earlier part of this investigation. A mechanical pump alone, without a mercury-diffusion pump, has served satisfactorily in most of the work. The vaporization indicator $H$ consists of a capillary $U$ tube containing a drop of vacuum-pump oil. The position of the $61114^{\circ}-27-2$ 
oil drop in the capillary shows whether higher pressure exists on the combustion tube side or the pump side of the indicator. When the evolution of gases from the iron tube $B$ and the combustion tube $C$ ceases after a short preliminary heating, and vaporization of the calcium begins, a higher vacuum may soon exist in the combustion tube than on the pump side of the indicator. The oil drop then moves slowly along the capillary toward the combustion tube. ${ }^{24}$ A by-pass $L$ of large bore permits rapid evacuation of the combustion tube at the beginning of a run but should be closed before the calcium vaporizes. The stopcock $J$ is used for the admission of dry carbon dioxide to the apparatus at the close of the absorption.

\section{REAGENTS}

(a) Metallic calcium.-Metallic calcium in lump form was found often to be very high in nitrogen (0.1 per cent) and not uniform in nitrogen content, particularly when slag inclusions are numerous. It can however, be secured in 1/2-inch diameter sticks, uniform in nitrogen and containing less than 0.01 per cent nitrogen. Such metal was found to be quite satisfactory. All slag and surface oxidation should be removed from the metal before use.

(b) Hydrochloric acid (sp. gr. 1.1).-Chemically pure concentrated hydrochloric acid is added to an equal volume of ammonia-free water. Such acid should give a blank of not greatly in excess of 0.000003 $\mathrm{g}$ nitrogen per $\mathrm{cm}^{3}$.

(c) Concentrated sodium hydroxide.-Three hundred grams of fused sodium hydroxide are dissolved in $500 \mathrm{~cm}^{3}$ of distilled water and heated for 24 hours at $50^{\circ} \mathrm{C}$. over a zinc-copper couple in order to reduce any nitrites that may be present. The zinc-copper couple is prepared by adding mossy zinc to a slightly warm saturated solution of copper sulphate. After about 15 minutes the solution is poured off, and the copper-covered zinc is washed carefully with distilled water.

(d) Standard sulphuric acid.-The standard sulphuric acid should be either 0.01 or 0.05 normal, depending upon the amount of ammonia to be absorbed from the distillation.

(e) Standard sodium hydroxide (free from carbonate).-The standard sodium hydroxide is either 0.01 or 0.05 normal, to correspond to the normality of the sulphuric acid used.

(f) Sodium alizarine sulphonate indicator.-A 1 per cent aqueous solution of sodium alizarine sulphonate is used as indicator in the standard acid-alkali titration.

\footnotetext{
${ }^{24}$ The indicator obviously is operative in the manner described only in case the vacuum pump is not capable of maintaining a pressure as low as is given by the vaporizing calcium.
} 


\section{DETAILED PROCEDURE}

A 2-gram piece of carefully cleaned calcium is placed in the closed end of the iron tube $B$. This tube is then slid into the combustion tube $C$ to such a position that the closed end of the iron tube is in the center of the furnace $A$. The cap of tube $D$ is replaced and the vacuum pump started. When the pressure in the combustion tube $C$ has been reduced to about $0.02 \mathrm{~mm}$, the current is turned on in furnace $A$. A blast of cold air is directed against the combustion tube at the position of the open end of the iron tube in order to cool the end of the iron tube and prevent the escape of any calcium vapor. During the heating the pressure within tube $C$ may rise as high as $0.5 \mathrm{~mm}$, due to gases evolved from the calcium and the iron tube. After the heating has continued for about 20 minutes and the combustion tube has attained a dull-red heat, stopcock $L$ is closed. At this time the pressure in the combustion tube is usually just enough greater than the pressure on the vacuum pump side of the vaporization indicator to keep the oil drop on the pump side of the capillary for about five minutes longer. When the calcium begins to vaporize, the oil drop moves slowly along the capillary toward the combustion tube. The stopcock $M$ is then closed. The tube connecting $M$ directly with $F$ and the induction furnace $G$ have been previously evacuated. As soon as the pressure within the furnace $A$ has dropped to 0.02 to $0.03 \mathrm{~mm}$, stopcocks $M$ and $F$ are turned to connect $C$ with $G$. The metal sample in $G$ is then melted and heated to $1,650^{\circ} \mathrm{C}$., and the gases are absorbed as fast as evolved. The pressure during the evolution of gas from the sample generally does not rise above $2 \mathrm{~mm}$. Approximately one hour is sufficient for the complete removal of gases from a normal metal sample. The pressure in the system when the heating of the sample is complete should be approximately the same as at the beginning of the heating period, namely, 0.02 to $0.03 \mathrm{~mm}$. The current in furnace $A$ is then turned off and the halves of the split furnace opened back from the combustion tube. Heavy asbestos boards are then placed over the hot furnace coils, and the combustion tube $C$ is cooled by a blast of air. When this tube has cooled nearly to room temperature, dry carbon dioxide is admitted through $J$ until atmospheric pressure within the system is indicated on the open-end manometer at $K$.

The iron tube is then removed from the combustion tube, and its loose contents, comprising the larger part of the fixation products, are emptied into a Pyrex glass tube $A$ (fig. 2), about 8 inches long, closed at the bottom and fitted at the top with a rubber stopper covered with tin foil, through which passes a separatory funnel $B$ and a delivery tube leading into a bubble tube $C$. The bubble tube 
contains small glass beads and has at the top small holes of such a size as to permit the passage of liquid but not the glass beads. Tube $A$ is surrounded by cold water in a glass cylinder $D$.

For the solution of the absorption products a total volume of 50 $\mathrm{cm}^{3}$ of hydrochloric acid (sp. gr. 1.1) are required as follows: $20 \mathrm{~cm}^{3}$ are diluted to $100 \mathrm{~cm}^{3}$ and placed in funnel $B ; 10 \mathrm{~cm}^{3}$ are poured into the bubble tube $C$; the remaining $20 \mathrm{~cm}^{3}$ are set aside for later use.

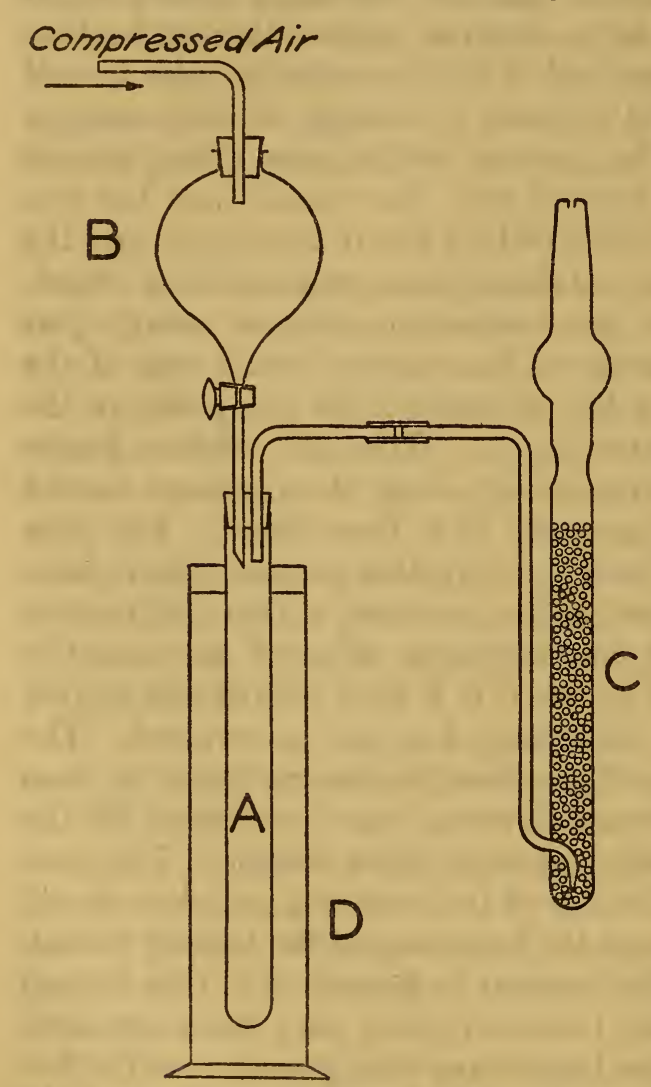

FIG. 2.-Solution tube for the decomposition of calcium nitride
The absorption products in $A$ are then dissolved by adding drop by drop about $20 \mathrm{~cm}^{3}$ of the dilute hydrochloric acid from $B$. After the first few drops have been added the pressure developed in $A$ makes it necessary to put pressure on the acid in $B$ in order to add any more to tube $A$. When the action has almost ceased, the contents of tube $A$ are poured into a $250 \mathrm{~cm}^{3}$ beaker bearing a mark at $200 \mathrm{~cm}^{3}$. Any solid matter remaining in $A$ is dissolved in the 20 $\mathrm{cm}^{3}$ of the stronger (sp. gr. 1.1) hydrochloric acid that had been set aside. In this case the use of the funnel $B$ and the bubble tube is not necessary.

The iron tube, containing some fixation product on its inner walls, is placed in a Pyrex glass tube similar to $A$ but about 17 inches long.

The remainder of the dilute acid in funnel $B$ is then dropped slowly into the iron tube, finally covering the tube inside and outside. The resulting solution is poured into the beaker containing the first portion, and the iron and glass tubes are washed thoroughly with distilled water. The washings are added to the main body of solution in the beaker. The solution in tube $C$ is poured into the beaker and the tube rinsed with distilled water into the beaker. The combined solutions in the beaker are then brought up to the $200 \mathrm{~cm}^{3}$. mark with distilled water. 
This solution is then treated in exactly the same manner as the sample solution in the usual acid solution method for nitrogen in steel. ${ }^{25}$ It is added, through a separatory funnel, to a distilling flask containing $30 \mathrm{~cm}^{3}$ of concentrated nitrogen-free sodium hydroxide and $200 \mathrm{~cm}^{3}$ of ammonia-free water. The condenser of the distillation apparatus is of block tin. About $200 \mathrm{~cm}^{3}$ of distillate are collected in a receiver containing a measured amount of 0.01 normal sulphuric acid. The excess acid is determined by titration with 0.01 normal sodium hydroxide with one drop of sodium alizarine sulphonate as an indicator. The end point is the complete loss of the original green color and is best judged by using for comparison a solution prepared by adding one drop of sodium alizarine sulphonate to a quantity of distilled water equal to that of the distillate.

\section{TESTS OF METHOD}

\section{BLANKS}

Blank corrections were determined at first for the reagents and apparatus exclusive of the induction furnace ( $G$, fig. 1$)$ and its contents. These blanks were determined by following the detailed procedure as already described, except that the induction furnace was not connected at any time to the absorption tube. The values for these blanks are given in Table 1. The first blanks (Nos. 1 to 5)

TABLE 1.-Nitrogen blanks: Total blanks on reagents and apparctus exclusive of induction furnace

\begin{tabular}{|c|c|c|c|}
\hline \multirow{2}{*}{ Blank No. } & \multirow{2}{*}{$\begin{array}{l}\text { Concentration } \\
\text { of solvent acid; } \\
\text { vol. conc. } \mathrm{HCl} \\
\text { to vol. } \mathrm{H}_{2} \mathrm{O}\end{array}$} & \multicolumn{2}{|c|}{ Values of blank as- } \\
\hline & & 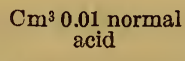 & Grams nitrogen \\
\hline $\begin{array}{l}1 \\
1 \\
2 \\
3 \\
4 \\
5\end{array}$ & $\begin{array}{l}1: 1 \\
1: 1 \\
1: 1 \\
1: 1 \\
1: 1\end{array}$ & $\begin{array}{l}1.51 \\
1.51 \\
1.56 \\
1.51 \\
1.56 \\
\end{array}$ & $\begin{array}{r}\mathbf{0 . 0 0 0 2 1 1} \\
.000211 \\
.0002218 \\
.000211 \\
.000218 \\
\end{array}$ \\
\hline A verage & . & 1.53 & .000214 \\
\hline 6 & $\begin{array}{l}1: 7 \\
1: 7\end{array}$ & $\begin{array}{l}.78 \\
.72\end{array}$ & $\begin{array}{l}.000101 \\
.000109\end{array}$ \\
\hline A verage & & .75 & .000105 \\
\hline
\end{tabular}

were made with the use of a somewhat more concentrated hydrochloric acid (namely, 1 part concentrated acid to 1 part water) for the solution of absorption products from the iron tube ( $B$, fig. 1) than is specified above in the detailed procedure. Very careful tests were then made to determine the distribution of the total blank (exclusive of the induction furnace). This distribution was determined as follows: (a) $50 \mathrm{~cm}^{3}$ of the 1:1 hydrochloric acid 
were added to the usual amount of sodium hydroxide solution in the distillation apparatus and the blank for the solvent acid and the distillation procedure were determined; $(b)$ then the usual 2 gram sample of metallic calcium was dissolved in $50 \mathrm{~cm}^{3}$ of the $1: 1 \mathrm{hydro}-$ chloric acid and the distillation made to give a blank which was the sum of the blank due to the calcium and the blank determined in $(a)$; (c) the iron tube was treated with the usual amount of the 1:1 solvent acid as for the solution of absorption products following a complete determination, and the usual distillation was made to give a blank which was the sum of the blank due to solution of iron from the tube and of the blank $(a)$. From these values were derived (1) the nitrogen blank of the calcium, $(b)-(a)$; (2) the nitrogen blank from the partial solution of the iron tube by the hydrochloric acid, $(c)-(a)$; and (3) the nitrogen blank from the solvent acid and the distillation procedure $(a)$. The difference between the sum of these three partial blanks and the average of blank runs Nos. 1 to 5 then represents the nitrogen blank due to the nitrogen absorption train alone. The values obtained for the distribution of the total blank were as follows:

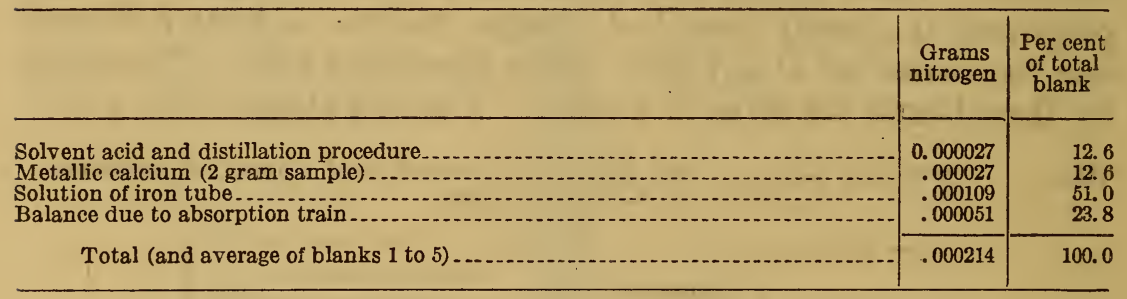

It is clear from these results that the partial solution of the iron tube in the 1:1 hydrochloric acid gave over 50 per cent of the total blank. ${ }^{26}$ The loss in weight of the iron tube amounted often to 2 or $3 \mathrm{~g}$ or more in a single run.

In order to eliminate that portion of the blank resulting from the attack of the iron tube by the rather concentrated acid, and also to increase the length of service of the iron tube, the absorption products in the iron tube were treated with a more dilute acid, the loosened contents of the tube were washed into a beaker, as described under "Detailed procedure" above, and any solid matter remaining in the solution was dissolved by adding more concentrated acid to the beaker. Blanks Nos. 6 and 7 (Table 1) were made using the same total amount of $1: 1$ hydrochloric acid as in the previous blank runs but diluting that portion of the acid used for treatment of the iron tube. The difference between the average of blanks 1 to 5 , run with concentrated acid, and the average of blanks 6 and 7 , run with dilute

\footnotetext{
${ }^{26}$ Some later results, however, indicate that this condition probably does not hold in the case of an iron tube which has been in use for some time and has been repeatedly heated in racuum.
} 
acid, is $0.000109 \mathrm{~g}$ of nitrogen, or the same as was obtained by solution of the iron tube in the concentrated acid. It is therefore evident that by the use of the dilute acid that part of the blank due to the attack of the iron tube by the solvent acid was entirely eliminated and the total blank reduced by approximately 50 per cent.

No higher blank was obtained for the entire apparatus, including the vacuum furnace containing the gas-free graphite crucible and magnesia insulator, than for the nitrogen absorption train alone. This was due to the fact that, after freeing the crucible and insulator of gases in the preliminary heating and cooling in vacuum, the vacuum was relieved with dry carbon dioxide. If, after the preliminary heating, the vacuum was relieved with dry air, very much higher nitrogen blanks were obtained.

\section{ANALYSES OF KNOWN GAS MIXTURES}

The method was tested with known mixtures of gases containing nitrogen. For such tests the gas burette containing the known gas mixture was attached to the nitrogen absorption train in place of the induction furnace ( $G$, fig. 1). Owing to the comparatively large amounts of nitrogen used in these tests the standard solutions for the absorption of the ammonia distillate and for titration were 0.05 normal instead of 0.01 normal as used in the analyses of metal samples. The data from tests on the absorption of commercially pure nitrogen, and of mixtures of nitrogen with oxygen, with oxygen and

TABLE 2.-Recovery of nitrogen from known gas mixtures by absorption by calcium

\begin{tabular}{|c|c|c|c|c|c|c|c|c|c|}
\hline \multirow{2}{*}{$\begin{array}{l}\text { Test } \\
\text { No. }\end{array}$} & \multirow{2}{*}{ Type of gas mixture } & \multicolumn{4}{|c|}{$\begin{array}{l}\text { Volume composition of gas } \\
\text { mixture }\end{array}$} & \multirow{2}{*}{$\begin{array}{c}\text { Gas } \\
\text { sample } \\
\text { taken }\end{array}$} & \multirow{2}{*}{$\begin{array}{l}\text { Nitro- } \\
\text { gen } \\
\text { taken }\end{array}$} & \multirow{2}{*}{$\begin{array}{l}\text { Nitro- } \\
\text { gen } \\
\text { found }\end{array}$} & \multirow{2}{*}{$\begin{array}{l}\text { Nitro- } \\
\text { gen re- } \\
\text { covery }\end{array}$} \\
\hline & & $\mathrm{N}_{3}$ & $\mathrm{O}_{2}$ & $\mathrm{CO}_{2}$ & $\mathrm{H}_{2}$ & & & & \\
\hline $\begin{array}{l}1 \\
2 \\
3 \\
4 \\
5 \\
6 \\
7 \\
8\end{array}$ & $\left\{\begin{array}{l}\text { Nitrogen } \\
\text { Nitrogen, oxygen } \\
\text { ditrogen, oxyde. } \\
\text { Nitrogen, hydrogen }{ }^{2} . . . . .\end{array}\right.$ & $\left\{\begin{array}{l}\text { Per cent } \\
1100 \\
1100 \\
78.1 \\
78.1 \\
19.9 \\
19.9 \\
29.6 \\
73.5\end{array}\right.$ & $\begin{array}{r}\text { Per cent } \\
21.9 \\
21.9 \\
5.6 \\
5.6 \\
\end{array}$ & Per cent & Per cent & $\begin{array}{r}c m^{3} \\
43.7 \\
38.9 \\
11.7 \\
6.5 \\
21.5 \\
16.1 \\
77.7 \\
32.1\end{array}$ & $\begin{array}{l}c m^{3} \\
43.7 \\
38.9 \\
9.14 \\
5.06 \\
4.30 \\
3.22 \\
23.0 \\
23.6\end{array}$ & $\begin{array}{l}\mathrm{cm}^{3} \\
43.0 \\
38.7 \\
9.14 \\
5.02 \\
4.33 \\
3.29 \\
22.7 \\
22.3\end{array}$ & $\begin{array}{r}\text { Per cent } \\
98.5 \\
99.5 \\
100.0 \\
99.5 \\
100.5 \\
102.0 \\
99.0 \\
95.0\end{array}$ \\
\hline
\end{tabular}

1 Commercial compressed nitrogen.

2 Nitrogen-hydrogen mixtures were saturated at $25^{\circ} \mathrm{C}$. with water vapor when admitted to calcium absorption tube.

carbon dioxide, and with hydrogen are given in Table 2. The mixtures of hydrogen with nitrogen were saturated with water vapor at room temperature before absorption in calcium. Practically complete recovery of nitrogen was secured in all these tests. 


\section{ANALYSES OF NITRIDES}

Analyses were made of nitrides of silicon, aluminum, titanium, zirconium, chromium, and vanadium both by vacuum-fusion and acid-solution methods. The aluminum nitride was kindly supplied by the Fixed Nitrogen Research Laboratory, of the United States Department of Agriculture, and the zirconium nitride by the Union Carbide and Carbon Research Laboratories (Inc.). Silicon nitride was prepared by direct nitrification of powdered 98 per cent silicon by heating at $1,300^{\circ}$ to $1,350^{\circ} \mathrm{C}$. in nitrogen. Powdered metallic titanium and chromium were nitrified in the same way, but using a small amount of hydrogen with the nitrogen, approximately 200 $\mathrm{cm}^{3}$ of hydrogen with $2,500 \mathrm{~cm}^{3}$ of nitrogen passing through the nitrifying furnace in an hour. Vanadium nitride was made by nitrifying in the same manner a mixture of vanadium trioxide and carbon. Attempts to form nitrides of tungsten, molybdenum, and cobalt in the same manner were not successful.

Analyses of nitrides were made by the acid-solution method, using, however, either hydrofluoric acid alone or a mixture of hydrofluoric and hydrochloric acids for the solution of the sample. ${ }^{27}$ In the case of those nitrides prepared by direct nitrification of the powdered metal, namely, silicon, titanium, and chromium, the gain in weight of the sample after heating in nitrogen might be expected to furnish some indication of the amount of nitride formed. This value, however, was found to be subject to error from oxidation of the powdered metal sample by oxygen which had not been completely removed from the nitrogen and also from losses of the powdered sample from the boat during nitrification. Only for silicon nitride did the nitrogen content as calculated from gain in weight, corrected for the oxygen content of the final product, ${ }^{28}$ compare closely with the maximum nitrogen found by analysis. The gain in weight of the silicon on nitrification was 13.35 per cent, and the nitrified silicon contained 1.07 per cent oxygen. The corrected calculated nitrogen content was therefore 12.28 per cent, while vacuum fusion analyses gave 12.31 per cent nitrogen as an average of three determinations. (Table 3.) For titanium nitride the gain in weight was 12.8 per cent, the oxygen content of the nitride 3.3 per cent, indicating a nitrogen content of 9.5 per cent. The fusion analyses of this nitride, however, gave 10.55 per cent nitrogen, indicating either a loss of sample from the boat during nitrification or that a considerable proportion of the oxygen content was

${ }_{27}$ The use of hydrofluoric acid alone or in mixtures was suggested in a private communication by T. $R$. Cunningham, of the Union Carbide and Carbon Research Laboratories (Inc.), as a modification of the acid-solution method which he had found useful in its application to the analysis of difficultly soluble nitrides.

${ }^{28}$ As determined by vacuum fusion. See footnote 10, p. 469. 
present originally in the titanium. The apparent gain in weight of chromium by nitrification was only 6.5 per cent, while fusion analyses indicated the presence of 10 per cent nitrogen. In all these cases, however, the recovery by fusion analysis of nitrogen equivalent to or greater than the apparent gain in weight of the metal during nitrification indicated that no considerable amount of nitride nitrogen escaped determination by fusion analysis.

The comparison of the amounts of nitrogen found in these nitrides by acid solution and by vacuum fusion indicates which method is the more suitable for any particular nitride. The results of the analyses of these nitrides are given in Table 3.

Appreciably more nitrogen was found by vacuum fusion than by acid solution in the case of the nitrides of silicon, titanium, and vanadium. Practically the same values for nitrogen were given by the two methods in the analysis of nitrides of aluminum, zirconium, and chromium. It is also interesting to note that the acid-solution method, using hydrochloric acid for solution of the sample, gave no indication of nitrogen in the vanadium nitride, a result which was checked by duplicate analyses.

TABLE 3.-Determination of nitrogen in metallic nitrides

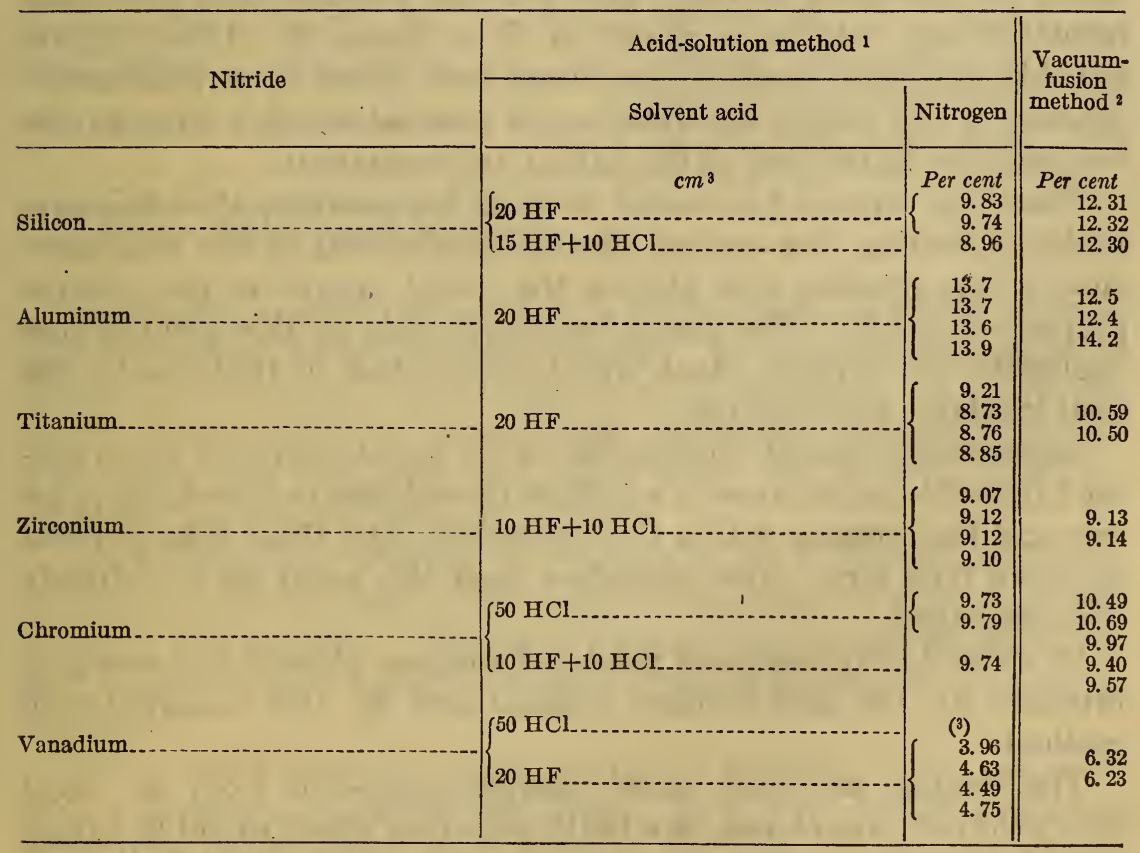

1 Samples of 0.15 to $0.20 \mathrm{~g}$ taken for analysis.

2 Samples of 0.05 to $0.10 \mathrm{~g}$ were heated to $1,650^{\circ} \mathrm{C}$., in vacuum with 20 to $30 \mathrm{~g}$ of electrolytic iron previously fused in graphite in vacuum.

3 Not detected. 
A temperature of about $1,650^{\circ} \mathrm{C}$. of the molten sample was sufficient for the recovery of nitrogen from all nitrides tested. It is probably desirable not to exceed this temperature unduly, as may be illustrated by the following case. Several analyses of aluminum nitride in which the temperature of the sample was $1,775^{\circ} \mathrm{C}$. resulted in values for nitrogen which were appreciably too low. At this higher temperature it is possible that reduction of the magnesia heat insulator by the graphite crucible produced magnesium vapor which reacted with some of the nitrogen evolved from the sample.

\section{ANALYSES OF IRONS AND STEELS}

The fusion of a metal sample for the determination of nitrogen is carried out in the high-frequency furnace with the same type and size of graphite crucible, magnesia heat insulator, and fused silica vacuum tube as is used in the vacuum-fusion method for oxygen. ${ }^{29}$ It is desirable to make all melts with a loosely fitting, cylindrical graphite plug over the sample in the crucible. This plug, floating on the molten sample, prevents loss of metal by spattering, and in some instances has been found to prevent appreciable loss of nitrogen.

This same procedure was followed in the test analyses of the nitrides as described above. The vacuum melting tube with heat insulator and crucible is shown at $G$ in Figure 1. This graphite crucible and heat insulator are freed from gases by a preliminary heating of the empty crucible in the evacuated silica tube to the temperature to be used in the actual determination.

When the furnace has cooled to room temperature after this preliminary heating, dry carbon dioxide is admitted to the evacuated tube before opening and placing the metal sample in the gas-free graphite crucible. The use of carbon dioxide at this point makes negligible the nitrogen blank due to adsorption of that gas by the heat insulator and crucible.

As previously stated, the heating of the metal sample in the evacuated tube $G$ is begun at such a time as the calcium is vaporizing properly and the pressure within the absorption tube $C$ has been reduced to about $0.02 \mathrm{~mm}$. The procedure from this point on has already been described.

In Table 4 are given some results of analyses of irons and steels for nitrogen by the acid-solution method and by the vacuum-fusion method.

The electric arc weld metal sample, deposited from an ingot iron weld rod, was chosen as a fairly pure iron which would be rather high in nitrogen. Since this weld metal would be practically free from alloying elements or impurities which might form nitrides, all the nitrogen determined by the acid-solution method should be

${ }^{20}$ See footnote 10, p. 469 of this paper, and also p. 476 of reference cited in footnote 10 . 
present as iron nitride. The two methods of analysis, acid-solution and vacuum-fusion, should, therefore, give the same result except for the possible determination of "uncombined" nitrogen by the fusion method. Actually the same result, 0.12 per cent nitrogen, was obtained by both methods. The vacuum-fusion method is indicated in the duplicate analyses to be of the same precision as the acid-solution method.

TABLE 4.-Determination of nitrogen in iron and steel samples

\begin{tabular}{|c|c|c|c|c|c|c|c|c|c|c|c|}
\hline \multirow{3}{*}{ Material } & \multicolumn{5}{|c|}{ Composition } & \multicolumn{5}{|c|}{ Nitrogen found by- } & \multirow{3}{*}{$\begin{array}{l}\text { Weight } \\
\text { of } \\
\text { sample } \\
\text { for } \\
\text { vacuum } \\
\text { fusion }\end{array}$} \\
\hline & \multirow[b]{2}{*}{ C } & \multirow[b]{2}{*}{ Mn } & \multirow[b]{2}{*}{$\mathbf{P}$} & \multirow[b]{2}{*}{ S } & \multirow[b]{2}{*}{$\mathrm{Si}$} & \multicolumn{2}{|c|}{$\begin{array}{l}\text { Acid solu- } \\
\text { tion with- }\end{array}$} & \multicolumn{3}{|c|}{ Vacuum fusion- } & \\
\hline & & & & & & HCl & HF & In & sample & $\begin{array}{l}\text { Blank } \\
\text { correc- } \\
\text { tion } \\
\text { applied }\end{array}$ & \\
\hline \multirow[t]{2}{*}{ Electric arc weld metal } & \multirow[b]{2}{*}{12.62} & P.ct. & P.ct & P.ct. & P.ct. & $\left\{\begin{array}{l}P . c t . \\
0.123 \\
.121 \\
.002\end{array}\right.$ & P.ct. & $\begin{array}{l}P . c t . \\
0.124 \\
.125 \\
.006\end{array}$ & $\begin{array}{c}g \\
0.001652 \\
.001274 \\
.000274\end{array}$ & $\begin{array}{c}g \\
0.000214 \\
.000214 \\
.000202\end{array}$ & $\begin{array}{l}g \\
1.33 \\
1.02 \\
5.0\end{array}$ \\
\hline & & 1.46 & 0.43 & 0.043 & 2.42 & $\begin{array}{l}.002 \\
.002\end{array}$ & & .006 & .000549 & .000202 & 10.0 \\
\hline $\begin{array}{l}\text { Charcoal cast-iron No. } \\
74\end{array}$ & 23.79 & & & .009 & 2. 47 & .001 & & .001 & .000206 & .000266 & 17.9 \\
\hline Coke cast-iron No. $23 \ldots$ & 3.64 & & & .026 & 2.44 & .001 & \} & .003 & .000414 & .000266 & 11.9 \\
\hline \multirow{2}{*}{$\begin{array}{l}\text { Silicon steel (lot 1) } \\
\text { Silicon steel (lot 2) }\end{array}$} & \multirow{2}{*}{$\begin{array}{l}.031 \\
.061\end{array}$} & \multirow{2}{*}{$\begin{array}{l}.090 \\
.058\end{array}$} & \multirow{2}{*}{$\begin{array}{l}.011 \\
.009\end{array}$} & \multirow{2}{*}{$\begin{array}{l}.005 \\
.027\end{array}$} & \multirow{2}{*}{$\begin{array}{l}4.00 \\
4.24\end{array}$} & $\begin{array}{l}.008 \\
.008 \\
.003\end{array}$ & $\begin{array}{l}0.008 \\
.009 \\
.003\end{array}$ & $\begin{array}{l}.010 \\
.010 \\
.006\end{array}$ & $\begin{array}{l}.001036 \\
.000990 \\
.000581\end{array}$ & $\begin{array}{l}.000256 \\
.000256 \\
.000256\end{array}$ & $\begin{array}{l}10.0 \\
10.0 \\
10.0\end{array}$ \\
\hline & & & & & & .003 & .004 & .005 & .000491 & .000256 & 10.0 \\
\hline
\end{tabular}

1 Total carbon. Combined carbon, 0.88 per cent.

Total carbon. Combined carbon, 0.36 per cent.

3 Total carbon. Combined carbon, 0.54 per cent.

Comparison analyses by the two methods were also made on three gray cast irons and on two silicon steels. All of these materials were of interest on account of their high content of silicon, one of the elements whose nitride is incompletely determined by acid solution. Two of the gray cast irons were made from coke pig iron, while the other was made from charcoal pig iron.

The acid-solution analyses of "cast iron $D$ " indicated a nitrogen content of 0.002 per cent, while duplicate analyses by vacuum fusion showed 0.006 per cent. The check vacuum-fusion analysis was made on a sample exactly twice the weight of the sample in the first determination.

Both methods gave the same value for nitrogen, 0.001 per cent, in the sample of charcoal cast iron. In a very similar cast iron, which was made, however, from coke pig iron, the vacuum-fusion method gave 0.003 per cent nitrogen as compared with 0.001 per cent by the acid-solution method.

Finally, analyses for nitrogen were made on two silicon steels (lots 1 and 2). These steels contained approximately 4 per cent 
silicon. The acid-solution method, using either hydrochloric or hydrofluoric acid, gave 0.008 per cent nitrogen in the first silicon steel and 0.003 per cent nitrogen in the second steel. The fusion method gave higher values for nitrogen in both cases, namely, 0.010 per cent nitrogen in the first steel and 0.006 per cent in the second.

The vacuum-fusion method thus gave the same result as the acidsolution method in the analysis of a comparatively pure iron containing rather high nitrogen, and the results by both methods were of practically the same precision. The vacuum-fusion method gave a higher nitrogen content than the solution method in the case of two coke cast irons and of two silicon steels. Out of the five highsilicon ferrous alloys examined only the single charcoal cast iron gave the same value for nitrogen by both methods of analvsis.

\section{SUMMARY AND CONCLUSIONS}

A method has been developed for the determination of nitrogen in the gases evolved from metals fused in vacuum. As in a previously described method for the determination of oxygen and hydrogen by vacuum fusion, the metal sample is melted in a graphite crucible in a high-frequency vacuum furnace. The nitrogen, together with the other gases evolved, except the noble gases, is absorbed in metallic calcium vapor. The nitrogen in the resulting calcium nitride is then determined by solution of all the products of absorption in dilute hydrochloric acid, addition of this solution to concentrated nitrogenfree sodium hydroxide, distillation of the nitrogen as ammonia, and collection of the distillate in standard sulphuric acid.

The efficiency of the absorption of nitrogen in calcium was determined with pure nitrogen and with known mixtures of nitrogen with oxygen, with oxygen and carbon dioxide, and with hydrogen. These tests showed that the absorption and recovery of nitrogen from mixtures of such gases as are ordinarily evolved from metals fused in vacuum is complete.

A comparison was made of the usual acid-solution method for determining nitride nitrogen and of the vacuum-fusion method in the analyses of several nitrides. Practically the same value for nitrogen was given by both methods in the analyses of aluminum; zirconium, and chromium nitrides. Appreciably higher recovery of nitrogen from silicon, titanium, and vanadium nitrides was given by the vacuum-fusion method. A temperature of approximately $1,650^{\circ} \mathrm{C}$. was used in the vacuum fusion of all nitrides.

The vacuum-fusion method as applied to samples of irons and steels indicated a precision as great as that obtained in the acid-solution method and in the case of four out of five samples of high-silicon ferrous alloys gave higher results for nitrogen than the solution method. 
The vacuum-fusion method as described should determine also "uncombined" nitrogen in a metal sample. The tests made with nitrides indicate that the fusion method may give a more nearly correct value for nitrogen than the solution method in the analysis of materials containing silicon, titanium, and vanadium.

Grateful acknowledgment is made to W. P. Barrows, R. J. Kranauer, and H. C. Vacher, all of the Bureau of Standards, for their assistance in making certain determinations of nitrogen and especially to $\mathrm{Mr}$. Barrows for the preparation of the nitrides of silicon, titanium, chromium, and vanadium.

WAshington, July 27, 1927. 